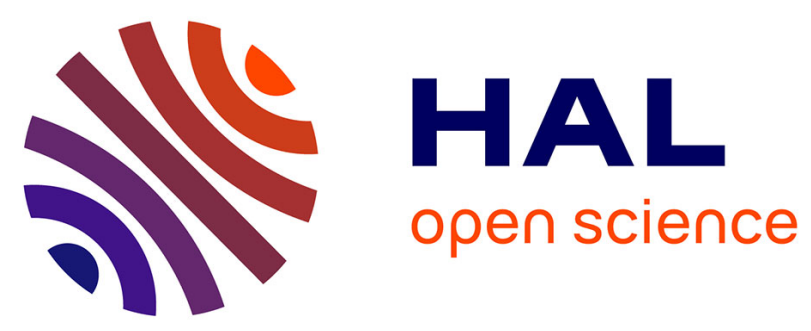

\title{
Slowing Down the Presentation of Facial and Body Movements Enhances Imitation Performance by Children with Severe Autism
}

France Lainé, Stéphane Rauzy, Carole Tardif, Bruno Gepner

\section{- To cite this version:}

France Lainé, Stéphane Rauzy, Carole Tardif, Bruno Gepner. Slowing Down the Presentation of Facial and Body Movements Enhances Imitation Performance by Children with Severe Autism. Journal of Autism and Developmental Disorders, 2011, 41 (8), pp.983-996. 10.1007/s10803-010-1123-7 . hal01491786

\author{
HAL Id: hal-01491786 \\ https://hal.science/hal-01491786
}

Submitted on 15 Feb 2018

HAL is a multi-disciplinary open access archive for the deposit and dissemination of scientific research documents, whether they are published or not. The documents may come from teaching and research institutions in France or abroad, or from public or private research centers.
L'archive ouverte pluridisciplinaire HAL, est destinée au dépôt et à la diffusion de documents scientifiques de niveau recherche, publiés ou non, émanant des établissements d'enseignement et de recherche français ou étrangers, des laboratoires publics ou privés. 
Slowing Down the Presentation of Facial and Body Movements Enhances Imitation Performance by Children with Severe Autism

\author{
France Lainé ${ }^{1}$, Stéphane Rauzy ${ }^{2}$, Carole Tardif $^{1}$, \& Bruno Gepner ${ }^{2,3}$ \\ ${ }^{1}$ Centre Psyclé, Recherche en Psychologie de la Connaissance, du Langage et des Emotions, \\ Université de Provence, France \\ 2 "Laboratoire Parole et Langage", CNRS UMR 6057, Université de Provence, France \\ ${ }^{3}$ Fédération Autisme Vie Entière, Hôpital Montperrin, Aix-en-Provence, France
}

Running head: Slowing down movements enhances imitation in autism

\begin{abstract}
Imitation deficits observed among individuals with autism could be partly explained by the excessive speed of biological movements to be perceived and then reproduced. Along with this assumption, slowing down the speed of presentation of these movements might improve their imitative performances. To test this hypothesis, 19 children with autism, 37 typically-developing children and 17 children with Down syndrome were asked to reproduce facial and body movements presented on a computer at a normal/ecological and two slowed down speeds. Our main result showed that a subgroup of individuals with severe autism better reproduced the movements when presented slowly than at the ecological speed. This finding opens a new window for comprehension and rehabilitation of perceptual and imitative deficits in autism.
\end{abstract}

Keywords

Autism, perception, imitation, biological motion, speed of information, slowing down communication

Corresponding authors: france.laine@univ-provence.fr bruno.gepner@univ-provence.fr 
Slowing Down the Presentation of Facial and Body Movements Enhances Imitation Performance by Children with Severe Autism

Although not clearly specified in nosographic classifications, difficulties imitating other people's actions and gestures have been consistently observed and documented among persons with autism since almost 40 years (De Meyer et al., 1972). These findings brought varying theoretical explanations and some contradictory findings in the literature due to a lack of consistent and operational definition of imitation and to the diverse methodologies used in the different studies (Sevlever \& Gillis, 2010, for a review). Beyond these considerations, the majority of the studies showed however that these impairments in imitation are common to a wide range of individuals with autism across varying IQ levels (i.e. either with or without intellectual disability) and severity of autism symptomatology (from severe to mild symptoms) (e.g. Avikainen, Wohlschlager, Liuhanen, Hanninen, \& Hari, 2003; Beadle-Brown \& Whiten, 2004; Dawson \& Adams, 1984; Rogers, Hepburn, Stackhouse, \& Wehner, 2003; Sigman \& Ungerer, 1984; Smith \& Bryson, 1998; Stieglitz Ham, Corley, Rajendran, Carletta $\&$ Swanson, 2008). These imitative deficits can be observed from the first year of life of individuals with autism (e.g. Osterling \& Dawson, 1994; Zwaigenbaum et al., 2005) and persist throughout childhood and adolescence (Heimann \& Ullstadius, 1999; Heimann, Ullstadius, Dahlgren, \& Gillberg, 1992; Stieglitz Ham, Bartolo, Corley, Rajendran, Szabo, \& Swanson, 2010). As imitation is a key indicator of communication in typically developing children and a good predictor of future social abilities (e.g. Nadel, 2006), impaired imitation might be considered a crucial contributor to the poor communication and social comprehension skills of children with autism.

Imitation deficit among children with autism was first supposed to be due to a lack of symbolic representation (Ohta, 1987) and was later seen as the first manifestation of a deficit in self-other mapping, creating a cascading effect in subsequent social skills (emotionsharing, joint attention, theory of mind) (Rogers \& Pennington, 1991). In the last decade, several studies suggested that imitation deficit in autism may be explained by a disorder in perception-action coupling due to a dysfunction of the mirror neuron system, which might lead to the self-other mapping deficit in autism (Oberman \& Ramachandran, 2007). According to this theory, individuals with autism should have impairments in both recognition and imitation of gestures. However, in a study aimed at exploring the relationship between gesture recognition and imitation, it was shown no correlation between these two variables, at least for some types of gestures (communicative gestures and gestures related to object use), demonstrating that imitative deficit of these types of gestures should be attributable to motor dyspraxia rather than to sensory motor integration deficit (Stieglitz Ham et al., 2010). Another study showed that individuals with autism were as much impaired in making a gesture in demand as in making it by imitation, demonstrating that the implication of a mirror neuron system dysfunction in the imitation deficit among individuals with autism is not found (Leighton, Bird, Charman, \& Heyes, 2008). Questions have also been raised as to whether deficits in imitation reflect more neurological impairments or perceptual, sensory motor integration or motor difficulties (Smith \& Bryson, 1994; Vanvuchelen, Roeyers, \& De Weerdt, 2007).

Impairments in attentional or perceptual processes, i.e. the first stages of the imitation process, might contribute importantly to the deficit of imitation in autism (see Vivanti, Nadig, Ozonoff, \& Rogers, 2008, for a detailed description). If this perception does not take place correctly or is distorted, the cascading processes cannot be intact. More precisely, perception of another's action is contingent on the ability to process the movement involved in this action, which can be considered a biological motion, because it is a movement from an animate being. 
In the current study, the focus is on the physical aspect of imitation rather than on its meaning or familiarity. The dual-route model of praxis processing proposes that two processes are involved in imitation (Rumiati \& Tessari, 2002). After the visual analysis, if the imitation concerns a meaningless action, i.e. that do not convey any general significance or goal and can be described only in terms of postures (Gowen, Stanley, \& Miall, 2008), action is imitated only using the processing route leading to the motor system, whereas if the imitation concerns a meaningful action, i.e. that has a semantic association, social significance or goal (Gowen et al., 2008), the action is imitated using both direct (non-semantic route) and semantic route. In fact, meaningful actions are stored in the long-term memory because they have been previously acquired. An example of a meaningless gesture might be striking each thigh with each hand in turn, whereas a meaningful one would include social significance or a goal, such as waving goodbye. More attention would be paid to the movement of the unfamiliar action of striking the thigh (meaningless action) to ascertain details such as the number of strikes or the amplitude of the movement, and less attention would be paid to the movement itself for a familiar gesture such as waving goodbye, which can be understood and reproduced with less accuracy. In this manner, understanding and reproducing meaningless gestures entail more attention to the execution of the movement, whereas meaningful gestures are imitated with respect to their goal even if details are ignored (Grézès, Costes, \& Decety, 1999; Bekkering, Wohlschlager, \& Gattis, 2000). A recent study showed that movement changes were reflected more accurately in the imitation of non-goal meaningless actions which can be attributed to direct visuomotor mapping of the action (Wild, Poliakoff, Jerrison, $\&$ Gowen, 2010). Some studies showed that individuals with autism are more impaired in reproducing meaningless gestures (see Williams, Whiten, \& Singh, 2004 for a review) whereas some other studies showed that they are impaired in the imitation of both meaningless gestures and meaningful ones (e.g. Vivanti et al., 2008; Stieglitz Ham et al., 2010).

Given that the aim of the present study is to examine the role of movement perception and especially the influence of the speed of gestures' presentation on imitation performances among individuals with autism, we chose to focus on meaningless gestures rather than on meaningful ones.

\section{Impairments in biological motion perception among persons with autism}

A growing body of fMRI and behavioral studies indicates that individuals with autism spectrum disorders (ASD) experience difficulty perceiving biological movements displayed either through point-light animations (e.g. Blake, Turner, Smoski, Pozdol, \& Stone, 2003; Freitag et al., 2008; Herrington et al., 2007; Klin, Lin, Gorrindo, Ramsay, \& Jones, 2009), or through real facial or body movements (Gepner, Deruelle, \& Grynfeltt, 2001). Impairments in biological motion perception among individuals with ASD could originally be due to problems in the perception and on-line processing of rapid movements or changes occurring in their visual environment (e.g. Gepner, Mestre, Masson, \& de Schonen, 1995; Gepner \& Mestre, 2002a,b; Rinehart, Tonge, Brereton, \& Bradshaw, 2010). As previously suggested (Welsh, Ahn, \& Placantonakis, 2005; Gepner \& Féron, 2009), such basic impairments would also result in slowed speed of information processing that was ascertained in several attentional, perceptual and cognitive tasks (Dawson, Webb, \& McPartland, 2005; McPartland, Dawson, Webb, Panagiotides, \& Carver, 2004; Webb, Dawson, Bernier, \& Panagiotides, 2006). Consequently, slowing down the presentation of biological movements may enhance their motion perception. Previous studies showed that, compared to typically developing children, children with autism better recognized and spontaneously imitated emotional and non-emotional facial expressions when they were presented slowly than when they were presented at a standard speed (Gepner et al., 2001; Lainé, Tardif, \& Gepner, 2008a; Tardif, 
Lainé, Rodriguez, \& Gepner, 2007). Furthermore, the degree of autism severity may be linked to the level of deficit in biological motion perception (as also shown by Blake et al., 2003), with the more severely affected children benefiting the most from a slower presentation speed in terms of performances on tasks of facial expressions recognition and of spontaneous imitation.

Based on the notion of impaired processing of biological motion among persons with autism, we hypothesized that, as it was the case with spontaneous imitation, requested imitation would be improved when the speed of presentation of the movement is slower. In a pilot study, it was found an improvement in the imitation of gestures by children with autism when gestures were presented slowly, whereas the speed of presentation had no impact on the imitation performances of typically developing children matched with the former on verbal and nonverbal mental age (Lainé, Tardif, Rauzy, \& Gepner, 2008b). However, this study cannot reveal whether the benefit of slowed down presentation was related to the developmental delay associated to autism, or to the autistic symptomatology per se. As the evidence that IQ is related to the speed of information processing, with the lower IQ being related to slower reaction times among adults and children with (Kail, 1992) and without intellectual disability (Grudnik \& Kranzler, 2001), individuals with intellectual disabilities might also need to perceive stimuli more slowly than individuals with average IQs. Accordingly, in order to control for IQ effects, we compared imitative performances of individuals with autism with those of persons with Down syndrome, a homogeneous intellectual disability (ID) of known etiology.

According to these observations, the present study included four aims. One was to investigate facial and body imitation in relatively low functioning children and adolescents with autism as compared to typically developing children and children and adolescents with ID, with the groups matched on verbal and nonverbal mental age, and on gender. The second was to replicate previous findings of the benefits of slowed down presentations of biological motion on imitative performances among children and adolescents with autism. The third was to examine whether the potential benefit of the slowed presentations might particularly enhance performance of participants with the more severe autistic behaviors. Fourth, the comparison between the participants with autism and those with intellectual disability allows us to investigate whether this benefit might be specific to autism or relevant more generally to intellectual disability. We predicted that the participants with autism would imitate worse than typically developing participants and participants with ID (Libby, Powell, Messer, \& Jordan, 1997), and that more of the severely affected children with autism would show improvement with slowed presentations.

\section{Participants}

\section{Method}

\section{The experimental group.}

The group with autism (AUT) was composed of 19 children and adolescents ( 4 girls and 15 boys), aged from $6 ; 4$ to $17 ; 6$ years $($ mean $=11 ; 8$ years - S.D. $=3 ; 8)$, diagnosed in accordance with DSM IV-TR criteria (APA, 2000) by an experienced child psychiatrist (BG). Participants were included if they received a diagnosis of autism only (i.e. those with Asperger syndrome or PDD-NOS were not included), without any comorbid disorder. They all had normal or corrected-to-normal vision. The severity of their symptoms was measured on the Childhood Autism Rating Scale (CARS, Schopler, Reichler, De Vellis, \& Daly, 1980), which has been shown to have a high level of agreement with the Autistic Diagnostic Interview-Revised (Pilowski, Yirmiya, Shulman, \& Dover, 1998; Saemundsen, Magnússon, Smári, \& Sigurdardóttir, 2003). The CARS's scores were assessed in all participants by the same child psychiatrist as well (BG), and revealed scores of between 31 and 38.5, ranging from mild 
autism to moderate-severe autism (according to the CARS manual, the minimum score for having a diagnostic of autism is 30). The experimental group was divided into three subgroups, according to the autism severity. The "severe" subgroup included children with a CARS's score above 37; the "moderate" subgroup included children with a score between 35.5 and 37; and the "mild" subgroup included children with a score between 30 and 35. Note that the notion of severe autism was relative here, the CARS threshold for severe autism being 38.5 (see table 2).

General imitation level of the participants with autism was assessed with the "Imitation" subscale of the CARS, and proved to range between mildly abnormal and moderately abnormal $(\mathrm{M}=2.3-\mathrm{SD}=0.51)$. Movements' coordination of the participants with autism was assessed with the "Body Use" subscale of the CARS, and proved to range between normal and moderately abnormal $(\mathrm{M}=2.26-\mathrm{SD}=0.48)$.

\section{The verbal mental age assessment and matching.}

The verbal mental age (VMA) of each child with autism was rated on the EVIP (Échelle de Vocabulaire en Images Peabody, Dunn, Thériault-Whalen, \& Dunn, 1993), which measures vocabulary comprehension. The participants had a VMA of between 2 and 10 years $($ mean $=4 ; 6$ years - S.D. $=2 ; 0)$. Measuring their VMA allowed us to ensure that they were capable of understanding the verbal instructions for performing the test, which required a minimum VMA of 2 years (Conscience, Schneider, \& Brasseur, 2003; Girard, 1996). It also enabled us to match them individually to typical children of a first control group (C-VMA, see below). As some individuals with autism in our sample had not developed an oral language, their level of expressive communication was not used to match participants with autism with the matched typically developing children and children with Down syndrome.

\section{The nonverbal mental age assessment and matching.}

The nonverbal mental age (NVMA) of each participant with autism was measured on the Progressive Matrix Coloured-Test (PMC-T, Raven, 1981) and two subtests (Triangles, Matrix Analogues) of the nonverbal scale of the Kaufman-Assessment Battery for Children (K-ABC, Kaufmann \& Kaufmann, 1993). On these measures, the participants achieved a NVMA of between 3;9 and 12;6 years (mean $=6 ; 10$ years - S.D. $=2 ; 5)$. Measuring their NVMA allowed us to match the subjects individually with typical children of (C-NVMA, see below) as well as with children with intellectual disability of known etiology (Down syndrome) (C-DS, see below). We were unable to match one of the participants with autism with a participant in each of the C-NVMA and C-DS groups, as his score on the NVMA assessment fell below the threshold. Another child with autism achieved a NVMA score of $12 ; 6$ years, an age which is difficult for an individual with Down syndrome to achieve. Thus, we were unable to match this child to one in the C-DS group.

\section{The Comparison Groups.}

The C-VMA comparison group included 19 typically-developing children, aged from $2 ; 2$ to $10 ; 1$ years $($ mean $=4 ; 7$ years - S.D. $=1 ; 11)$, who were matched individually to the children with autism for gender and VMA.

The C-NVMA comparison group included 18 typically-developing children, aged from $3 ; 9$ to $12 ; 6$ years $($ mean $=6 ; 10$ years - S.D. $=2 ; 5)$, individually matched to the children with autism for gender and NVMA.

None of the typically developing comparison children of both groups had been diagnosed with an ASD or intellectual disability, nor had a history of neuropathology or other psychiatric illness. They all had normal or corrected-to-normal vision.

The C-DS comparison group included 17 children and adolescents with Down syndrome, aged from $6 ; 11$ to $19 ; 11$ years $($ mean $=14 ; 5$ years - S.D. $=3 ; 5)$, individually 
matched to the children with autism for gender and NVMA. The sex ratio for Down syndrome is 1:1 (Abbeduto, Warren, \& Conners, 2007; Sherman, Allen, Bean, \& Freeman, 2007), whereas it is approximately 4:1 (male to female) for autism (Fombonne, 2003), making it difficult to perform exact matching on the basis of gender. The children and adolescents of this group were included in the study when they presented no comorbid disorder. They all had normal or corrected-to-normal vision.

The characteristics of the participants in the different groups are summarized in Table 1.

\section{[Insert table 1 about here]}

In order to determine whether the motion perception disorder is linked with the autistic symptomatology or with the intellectual level (i.e. the mental age), we divided the participants of all groups into 3 subgroups according to their NVMA and their VMA (see table 2).

[Insert table 2 about here]

\section{Material}

Filmed sequences.

A woman (the model) was filmed with a webcam, while displaying 20 facial or body meaningless gestures. The gestures were inspired either from various standardized imitation batteries (K-ABC, Kaufman \& Kaufman, 1993; PEP-R, Psycho-Educational Profile Revised, Schopler, Reichler, Bashford, Lansing, \& Marcus, 1994; Gesture Test, Cermak, Coster, \& Drake, 1980) or from batteries used in other studies (Beadle-Brown \& Whiten, 2004; Green et al., 2002) (see appendix and figure 1).

The gestures were displayed at a reference ecological speed named S1 (see below). At this speed, each gesture lasted about 2 seconds. To obtain this ecological speed, we asked the woman to make the gesture as if somebody would have to reproduce it afterwards. The gestures were repeated and recorded several times, and there were only subtle differences in the timing of the different essays. The most accurate essay was then chosen for the experiment. The same operation was repeated for all the gestures.

The 2-seconds filmed sequences of the 20 gestures were then implemented on a laptop computer (DELL® Latitude D600).

\section{[Insert figure 1 about here]}

\section{Software program and task description.}

A computer software program, specially designed for the experiment, was implemented on the computer. It aimed at reducing the speed of a signal made up of a video input (the output of the camera used to film the model). Via the software program, the reference speed S1 of the model's gestures was slowed down in a systematic manner, at two different speeds: i) a "slow" speed, named S2, which corresponded to S1 slowed down by a factor of 2: at this speed, each sequence lasted 4 seconds, and ii) a "very slow" speed, named S3, which corresponded to S1 slowed by a factor of 2.5: at this speed, each sequence lasted 5 seconds. Each sequence was defined by a parameter file specifying the slowed-down speed. We therefore obtained 60 filmed sequences, i.e. the 20 initial sequences presented at 3 different speeds (S1, S2, S3). This set-up was completed by a graphical user interface used to display the stimulus sequences to the participant. The 60 sequences were then recorded in a random order, and ready to be displayed to the participants on the computer screen. 


\section{Procedure}

The participants were tested individually in a quiet room, either in their child day care psychiatric unit or special school for handicapped children, or at their regular school, in Marseille, Aix-en-Provence and suburbs. Each participant first passed the EVIP, then the K$\mathrm{ABC}$ and PMC-T and to finish the experimental tasks. Before starting the scoring of the experimental tasks, we first administered a series of 4 examples demonstrating what the participants would be asked to do. Each participant was asked by the experimenter to look at the first sequence on the computer screen carefully and to reproduce the gesture he/she had seen at the end of the sequence. At the end of each sequence, the screen went blank in order to elicit a gesture based on the entire dynamic set of movement the children had seen, rather than on the final static image still in front of them. After the participant had produced a gesture, the experimenter scored his/her gesture. Then the second sequence was displayed, and so on.

\section{Scoring}

Scoring was designed to reflect the completeness of imitation. If the child reproduced the entire gesture completely, he/she scored 2 points (for example, if the gesture implies to stretch out fingers, with palm facing the floor, then rotate hand until facing the ceiling, the child has to reproduce every step of this gesture from the beginning to the end exactly in the same order). If the reproduction was incomplete (e.g. the child rotates his/her hand but doesn't stretch out his/her fingers), only 1 point was awarded. Lastly, if the child failed to reproduce any part of the gesture at all, or performed an entirely different movement, he or she scored 0 . Each child could therefore have a total score of between 0 and 120 . Ten percent of the entire data set was coded by two raters to calculate interrater reliability, using intraclass correlation, which was high (.80).

\section{Data analysis}

The data were subjected to a repeated-measures ANOVA (4 (Group) x 3 (Presentation speed)), with the imitation score as the dependent variable and the presentation speeds as the repeated measures. For the post-hoc analyses, we used Tukey's HSD.

In order to compare the effects of the slower presentations on the performances of the children between subgroups according to the NVMA, the VMA and the severity of autism, we chose to perform the nonparametric chi square test as we were comparing actual numbers, not means. We consider the Fisher exact probability test for the significance threshold because the Fisher exact is more conservative and appropriate for small sample (Chanquoy, 2005; Howell, 2009). We deemed that a child had benefited from a slowed down presentation if he/she scored at least 2 points more with one of the two slower presentation speeds (S2 and/or S3) than with the reference speed (S1). We also compared the overall imitation performance between the three subgroups with autism - according to i) the severity of autism, ii) the NVMA and iii) the VMA - and between subgroups with autism and subgroups of the comparison groups. As each subgroup comprised few participants (between 5 and 7 depending on the subgroup), a non-parametrical calculation was used (i.e. U of MannWhitney) to compare the rank of the scores instead of the mean.

\section{Results}

A between group analysis of the participants' imitative performances revealed a simple effect of the "group" variable $\left[F(3,69)=5.3, p=0.002 ; \eta^{2}=0.19\right]$ (see fig. 2). Post-hoc analyses revealed that the AUT group performed more poorly than the C-VMA $(p=0.02)$ and C-NVMA groups $(p=0.002$ ), but not than the C-DS group ( $p=0.13$ ) (AUT group: $\mathrm{M}=80.79-$ $\mathrm{SD}=27.36$; $\mathrm{C}-\mathrm{VMA}$ group: $\mathrm{M}=99.05-\mathrm{SD}=12.70 ; \mathrm{C}-\mathrm{NVMA}$ group $=\mathrm{M}=104.94-\mathrm{SD}=$ 14.05; C-DS: $\mathrm{M}=96.12-\mathrm{SD}=15.6)$. 
The overall score in imitation of the participants of the AUT group is negatively correlated with the CARS' score, i.e. participants with the highest CARS' score (revealing the most severe autism) are those having the lowest score in imitation $(\tau=0.64, p=0.0001)$.

When the group with autism is divided into three subgroups, according to the severity of autism, participants with mild autism perform better than both participants with moderate autism (participants with mild autism: $\mathrm{M}=107.17, \mathrm{SD}=11.28$; participants with moderate autism: $\mathrm{M}=86, \mathrm{SD}=12.85 ; \mathrm{Z}=2.28, \mathrm{p}=0.022)$ and participants with severe autism $(\mathrm{M}=$ $53.17, \mathrm{SD}=23.35 ; \mathrm{Z}=2.88, \mathrm{p}=0.004)$. Note that the former obtained near ceiling scores that probably left little room for progression. Participants with moderate autism also performed better than participants with severe autism $(Z=2.42, \mathrm{p}=0.015)$.

According to the level of VMA, participants with autism having the lower VMA performed worse in imitation than participants with autism having middle and high VMA $(\mathrm{Z}=-2.27, \mathrm{p}=0.028$ and $\mathrm{Z}=-2.12, \mathrm{p}=0.03$, respectively). No significant difference was found according to the level of NVMA ( $\mathrm{Zs}>-1.68$, ps $>0.09$ ). Comparisons with other groups reveals that participants with autism having the highest VMA and NVMA performed equally as well as children with DS and typically-developing children (all $\mathrm{Zs}>-1.2$, all ps $>0.229$ ), whereas participants with autism having either a middle or low VMA or NVMA performed worse than typically-developing children and children with DS $\left(\mathrm{Zs}_{\mathbf{s}}<-1.98\right.$, ps $\left.<0.047\right)$.

\section{[Insert Figure 2 about here]}

Second, we observed no significant effect of the "presentation speed" variable $[F(2$, $\left.138)=1.73, p=0.18 ; \eta^{2}=0.02\right]$ and of the "group $\mathrm{x}$ presentation speed" interaction $\left[F(6,138)=0.98, p=0.44, \eta^{2}=0.04\right]$ (see fig. 2). Levels at the two subscales of the CARS, "Body Use" and "Imitation", were not correlated to the impact of the speed of presentation on the performances of the AUT group $(\tau<0.22, \mathrm{p}>0.19)$.

[Insert Figure 3 about here]

However, when the AUT group was divided into three subgroups according to the autism severity, more of the members of the "severe" subgroup benefited from the slower presentations than the members of the "moderate" and "mild" subgroups $\left(\chi^{2}=4.27 ; p=0.008\right.$; $\varphi=0.57$ and $\chi^{2}=6 ; p=0.01 ; \varphi=0.71$, respectively) (see table 3 ). No difference was found between the members of the "moderate" subgroup and those of the "mild" subgroup $\left(\chi^{2}=\right.$ $0.03 ; p=0.85 ; \varphi=0.05)$. Moreover, all the children with severe autism were helped by the slower presentations, which was not the case for their "moderate" or "mild" counterparts (see table 3).

When the children with autism were divided into three subgroups according to their VMA, it was found that more of the members of the low VMA subgroup benefited from the slower presentations than the members of the middle VMA subgroup $\left(\chi^{2}=6.35 ; p=0.02\right.$; $\varphi=0.63$ ). The other comparisons did not reach the significance (low VMA subgroup versus high VMA subgroup: $\chi^{2}=0.03 ; p=0.53 ; \varphi=0.05$ - middle VMA versus high VMA: $\chi^{2}=0.5$; $p=0.24 ; \varphi=0.20$ ).

When the children with autism were divided into three subgroups according to their NVMA, no subgroup was helped by the slowed down presentations $\left(\chi^{2}<3 ; p \mathrm{~s}>0.12\right)$.

None of the difference between subgroups in each comparison group reached the significance (for C-VMA: $\chi^{2}<2.86 ; p \mathrm{~s}>0.12$; for C-NVMA: $\chi^{2}<0.63 ; p \mathrm{~s}>0.41$; for C-DS: $\chi^{2}<3$; ps $>0.12$ ). 


\section{Discussion}

This study aimed at measuring facial and body imitation in autism, and more specifically the impact of the speed of presentation of facial and body movements on imitative performances of individuals with autism compared to these of typically developing participants and participants with Down syndrome. Our main findings showed that i) children with autism scored significantly lower on imitation of gestures than the typically developing children, but not than those with Down syndrome, ii) the whole group of children with autism did not imitate better when the gestures were slowed down than when they were presented at normal speed but, as expected, iii) the most affected children with autism in our sample benefited more from slowed down presentation than the less affected ones. Conversely, no other subgroups of comparison participants displayed such a benefit. Overall, although the benefit of slowed presentation was not systematically observed in the whole group but only among participants with the most severe autism, it seems however to be specific to autism, and also related to the severity of the syndrome.

\section{Overall imitation performance}

Given the data on imitation of action in individuals with autism showing a general deficit in imitating another's actions we had assumed that the participants with autism in our study would imitate the model's gestures less successfully than typically developing participants. This assumption proved correct. The overall imitation performance among participants with autism was significantly worse than among the typically developing children matched either on VMA or NVMA. Our results also show that participants with autism having low and middle VMA performed worse in the imitation task than their typically developing VMA-matched children, whereas participants with autism having higher VMA performed equally as well as their typically developing VMA-matched comparison children. As consistently shown earlier (e.g. Stone, Ousley, \& Littleford, 1997; Rogers et al., 2003), there is a relationship between the level of language development (here, the level of vocabulary comprehension) and imitation performances in autism. Moreover, our finding shows that the most severe autism, including the most social impairments, is associated with the lower imitation performances, which is also in line with previous studies (e.g. Rogers et $a l ., 2003)$. Imitation is a key indicator of communication, especially in typically developing preschoolers (Nadel, 2006), and promotes the acquisition of pragmatics (Nadel, Guérini, Pezé, \& Rivet, 1999; Nadel \& Pezé, 1993), the construction of the self and differentiation between self and non-self (Wallon, 1934), the ability to attribute agency and intentionality (Meltzoff, 2007; Nadel \& Potier, 2002; Russell, 1990), and the ability to attribute mental states (Rogers \& Pennington, 1991). Imitation is, therefore, a good predictor of a child's future social abilities. Consequently, in people with autism, impaired imitation contributes to poor communication and comprehension of the social world. Our results confirm that there is a link between severity of autism, language development and imitation performance but still, do not explain why and how such a link exists.

\section{Biological motion perception: Impact of the speed of movements' presentation}

As said in Introduction, questions have been raised as to whether deficits in imitation reflect more i) perceptual, ii) sensory motor integration or iii) motor difficulties (Smith \& Bryson, 1994; Vanvuchelen et al., 2007). Given a growing body of data, we assumed that disordered perception and sensory motor integration of physical and biological movements (particularly the rapid ones) among individuals with autism could explain cascading effects and result in many of their motor, imitative, communicative and social symptoms (Gepner \& Mestre, 2002a; Gepner \& Féron, 2009 for a review). 
Contrary to our expectations the group of participants with autism as a whole, compared to the three other groups of participants, did not benefit from slowed presentations of facial and body movements. It could be concluded that imitation deficits in individuals with autism would not be based on a rapid visual-motion processing deficit. Another interpretation is that the experimental display is not sensitive enough to reveal a positive impact of slowed presentations of facial and body movements on imitation in our group with autism as a whole. The fact that participants with mild autism obtained ceiling or near ceiling scores of imitation, leaving only little opportunity for progression, is in favour of this second interpretation. Besides, even though abnormal imitation has also been demonstrated in Asperger syndrome or high-functioning autism individuals (Avikainen, Wohlschlager, Liuhanen, Hanninen, \& Hari, 2003; Nishitani, Avikainen, \& Hari, 2004; Stieglitz Ham et al., 2008), previous studies on motion perception in autism (e.g. Blake et al., 2003; Gepner \& Mestre, 2002b), and several self-reports of autistic adults (e.g. Williams, 1992; Grandin, 1995) suggested that there is a gradient of deficit in motion perception in the autistic population, the most severely affected persons displaying the most impaired motion perception, as seen for instance on facial expression recognition task (Tardif et al., 2007) and on imitation task (Lainé et al., 2008b). These arguments altogether are consistent with the second interpretation, and led us to further investigate the impact of slowed presentations of gestures on imitation performance in participants with autism according to the severity of their syndrome, as well as to their level of VMA and NVMA.

As expected, more of the participants of the "severe" autism subgroup benefited from the slower presentations of facial and body movements than children having moderate or mild autism. However, as said above, it is worth mentioning that children and adolescents with mild autism reached or almost reached ceiling performances. The lack of significant benefit from slowed presentations in the whole AUT group could partly be due to this ceiling effect. Half of the participants with mild autism had scores of between 112 and 120 (120 being the maximum score). Within the remaining half, scores were of between 104 and 78, and twothirds of this subgroup had better performance in slowed speeds. The same trend was observed within the participants with moderate autism. When examining results in this way, one can see that participants with mild or moderate autism who did not obtain the maximum score have been helped by the slow speeds. Future studies should involve a larger sample of participants with a larger spectrum of autism severity and should also propose movements with graduated complexity.

Besides, children with autism who had the lowest VMA also benefited the most from the slowed down presentations of movements as compared to those with the moderate VMA. However, the comparison between low and high VMA children with autism did not reach significance, making these results inconsistent: a replication of this study including children with autism having a larger range of VMA levels should also be conducted. In parallel, none of the subgroups of the C-VMA comparison group benefited from slowed presentations. None of the subgroups of participants benefited from slowed presentations when the 3 groups of participants were divided according to their NVMA neither (AUT group, C-NVMA and C-DS groups). Although the benefit of slowed presentations of facial and body movements on imitation was not significant in any of our groups of participants as a whole, the slowed presentations of facial and body movements enhance imitative performances among the persons with autism with most severe autistic symptomatology. The benefit of slowed presentations of facial and body movements seems therefore to be specific to autism, and related to the severity of the syndrome.

Finally, since the biological movements used in our study involved a person, and therefore had a social component, we do not know whether the deficits observed in participants with autism are perceptual in general rather than a phenomenon that occurs only 
in social situations (Klin, Jones, Schultz, \& Volkmar, 2004). Several observations already provided preliminary evidence of the presence of motion perception disorders independent from the existence of a social processing disorder in autism. First, a study revealed that biological motion processing deficit in autism cannot be explained by the need to process emotional content of the stimuli (Cook, Saygin, Swain, \& Blakemore, 2009). Second, motion and temporal perception disorders using non social paradigms were found in autism (e.g. Gepner et al., 1995; Spencer et al., 2000; Milne et al., 2002; Rinehart et al., 2010). These findings are consistent with a general motion perception deficit in autism (Kaiser \& Shiffrar, 2009), particularly when the speed of motion is high (Gepner \& Féron, 2009). These findings suggest that children with severe autism were helped by the slowed presentations because they might need more time to read biological motion information, and not social information, in the model.

Overall, our results show that some children with autism, mainly but not only those with rather severe autism and low verbal level, present enhanced imitative performances when the facial and body movements to be imitated are slowed down. This main result is in line with the rapid visual-motion perception and integration deficit hypothesis of autism (Gepner $\&$ Mestre, 2002a), which constitutes one example of temporo-spatial processing disorders of multi-sensory flows in autism (Gepner \& Féron, 2009).

\section{Motor and sensory motor explanations}

Other explanations should be examined to account for imitation deficit in our sample of participants with autism. In particular, their low imitation performances compared to those of typically developing comparison children could also be explained by motor impairments. Although they had normal to moderately abnormal scores at the two subscales of the CARS "Body Use" and "Imitation", their scores were however not correlated to the impact of the speed of presentation of facial and body movements in the AUT group $(\tau<0.22, p>0.19)$, i.e. the possible benefit of the reduced speed of gestures on their imitation performances is not correlated to these motor items.

In the literature, several studies previously showed that motor impairments of children with autism were not always sufficient to explain their imitation deficit (Rogers, Bennetto, McEvoy, \& Pennington, 1996; Rogers et al., 2003; Stieglitz-Ham et al., 2008, 2010) and that such impairments do not appear to be specific to imitation (Mostofsky et al., 2006). The contribution of motor abilities to imitation in autism ranges from 0 to $80 \%$ across the studies (Bennetto, 1999; Rogers et al., 2003; Smith \& Bryson, 1998; Vanvuchelen et al., 2007), depending on what type of instruction and task the participants have to do, and consequently depending on imitative demands inherent to the instructions. For instance, Dewey, Cantell, and Crawford (2007) conclude in their study that even when level of motor skills was controlled for, the gestural impairments found in children with autism in performing gestures to command and imitation are not only due to deficits in motor coordination. Besides, some authors tend to show the existence of limb apraxia in autism, which could have repercussion in imitation performances in this population (Stieglitz-Ham et al., 2010). Dyspraxia in autism could be, at least in part, due to problems with transforming spatiotemporal representations of movements into the motor sequences necessary to accurately perform skilled gestures (Steiman, Mostofsky, \& Denckla, 2010). For instance, Dowell, Mahone and Mostofsky (2009) suggested that visual perception impairments should be considered in the interpretation of findings on praxis performances in order to add temporal sequencing to spatial configuration. Finally, it was recently found no evidence that either motor or attentional aspects of imitation tasks contributed to the poorer imitative performance of children with autism (Rogers, Young, Cook, Giolzetti, \& Ozonoff, 2010). 
To summarize, even if motor impairments are often present in children with autism and could partly explain their imitation deficit, other components such as visual motion perception or visuo-motor integration deficits (as already shown in autism with physical movements, e.g. Gepner \& Mestre, 2002b) could strongly contribute to such imitation deficit too.

\section{Autism compared to Down syndrome}

Participants with Down syndrome performed worse in imitation tasks than their typically developing children. However, they did not perform significantly better than participants with autism, which is inconsistent with previous finding revealing that the imitative skills of children with Down syndrome were better than among children with autism (Libby et al., 1997).

As we also wanted to know whether the benefit of slowing down the speed of presentation of biological movements on imitation performance could be observed in other populations, we examined the possibility of such a benefit among children with Down syndrome (DS). We did not find any significant benefit from slowed down presentations nor in the whole group of DS participants, neither in any of the 3 subgroups divided according to NVMA. However, given that imitation performance and verbal level are generally correlated in autism (Rogers et al., 2003), we cannot rule out the possibility that one or more of the subgroups of DS participants would have benefited from slowed presentations if they had been divided according to VMA. A further study should take the VMA of participants with DS into consideration.

Although individuals with autism and those with Down syndrome both present imitation deficits, it seems that the underlying mechanisms are somewhat different in the two different groups: Participants with DS are apparently less sensitive to the reduced speed of the biological movements than those with autism.

Motor impairments among children with Down syndrome could explain their lower performances compared to those of the typically developing children. The attainment of early motor milestones, such as grasping, sitting, walking, occurs across wide variability from one individual with Down syndrome to another (Spanò et al., 1999). Such motor impairments might thus negatively influence imitation performances of individuals with Down syndrome. Temporal aspects of anticipatory actions and dynamic aspects of action perception could explain their motor impairments (Henderson, Morris, \& Frith, 1981) and consequently their poor imitation performances. Finally, some studies also revealed anatomical and structural brain differences in individuals with Down syndrome, namely in some areas involved in the visual analysis of human motion (Nadel, 1999), as well as a slow information processing speed in general (Zelazo \& Stack, 1997), possibly also contributing to imitation deficits.

To summarize, the difficulty of individuals with Down syndrome reproducing gestures might also arise from complex impairments in action perception and integration, whose exact nature and similarities/discrepancies with those of individuals with autism are still unknown and should be further explored.

\section{Visual attention to the gestures}

The aim of our study was to examine whether imitation deficits in autism could be partly explained by impairment in movement perception. As said in introduction, the gestures displayed in the present study were meaningless in order to investigate imitation of movement per se: as no significance was associated to the gestures, individuals could not use mechanisms of social learning and/or their personal experience to reproduce the gestures. Our results suggest that at least some participants with autism present movement perception impairments that could explain their imitation deficits. 
Interestingly, in an imitation study, Vivanti et al. (2008) showed that children with autism displayed qualitatively similar patterns of visual attention compared to typically developing children: They looked at the region of the action for the same amount of time, and they also looked at the region of the face as well as typically developing children, but with a decreased amount of time. Moreover, the duration of visual attention to the model's action was related to imitation accuracy for meaningless gestures in children with autism. In our study, we might assume that slowing down the gesture possibly allowed the children and adolescents with autism to look at the correct regions on the video and therefore imitate better. This crucial point needs further exploration using eye tracking measures in order to further apprehend the explanatory part of motion perception processing and that of visual attention on the improvement of imitation in individuals with autism.

\section{Neurobiological correlates}

A recent study on imitation using blood oxygen level dependent (BOLD) fluctuations showed atypical connectivity within the imitation network (inferior frontal gyrus, inferior parietal lobule, and superior temporal sulcus) in adults with autism (Shih et al., 2010). As also recently suggested (Gepner \& Féron, 2009), the biological movement perception and imitation deficits observed among individuals with autism might be linked to a pattern of functional disconnectivity (i.e. under- and/or over-connectivity) between several areas involved in movement and temporal processing and perception-action coupling, such as the magnocellular pathway (McCleery, Allman, Carver, \& Dobns, 2007), the dorsal stream (Villalobos, Mizuno, Dahl, Kemmotsu, \& Müller, 2005), the cerebellum (Allen \& Courchesne, 2003), the superior temporal sulcus (Hadjikhani, Joseph, Snyder, \& TagerFlusberg, 2007), and the mirror neuron system (Oberman et al., 2005; Dapretto et al., 2005). In this context, rapid movements may increase or at least reveal this disconnectivity, whereas slow movements may decrease this disconnectivity, possibly enhancing biological motion perception and imitation among the participants with autism. Future studies could further test this hypothesis.

\section{Final conclusion}

Slowing down the delivery of dynamic visual information with the help of our software enhanced the imitative performances of some of the children and adolescents with autism. Our findings may, therefore, open a new window for the comprehension and rehabilitation of perceptual and imitative deficits in autism. Adapting this software for individuals with autism in a more ecological way may help to improve their social integration by providing the opportunity to better perceive, understand, and imitate other people. 
Abbeduto, L., Warren, S. F., \& Conners, F. A. (2007). Language development in Down syndrome: From the prelinguistic period to the acquisition of literacy. Mental Retardation and Developmental Disabilities Research Reviews, 13, 247-261.

Allen, G., Courchesne, E. (2003). Differential effects of developmental cerebellar abnormality on cognitive and motor functions in the cerebellum: an fMRI study of autism. American Journal of Psychiatry, 160, 262-273.

American Psychiatric Association (2000). Diagnostic and statistical manual of mental disorders, $4^{\text {th }}$ edition, text revision. Washington, DC: American Psychiatric Association Press.

Avikainen, S., Wohlschlager, A., Liuhanen, S., Hanninen, R., \& Hari, R. (2003). Impaired mirror-image imitation in Asperger and high-functioning autistic subjects. Current Biology, 13, 339-341.

Beadle-Brown, J. D., \& Whiten, A. (2004). Elicited imitation in children and adults with autism: Is there a deficit? Journal of Intellectual \& Developmental Disability, 29, 147163.

Bekkering, H., Wohlschlager, A., \& Gattis, M., (2000). Imitation of gestures in children is goal-directed. Quarterly Journal of Experimental Psychology A, 53, 153-164.

Bennetto, L. (1999). A componential approach to imitation and movement deficits in autism. Dissertation Abstracts International, 60, 08-19.

Blake, R., Turner, L. M., Smoski, M. J., Pozdol, S. L., \& Stone, W. L. (2003). Visual recognition of biological motion is impaired in children with autism. Psychological Science, 14, 151-157.

Cermak, S. A., Coster, W., \& Drake, C. (1980). Representational and non-representational gestures in boys with learning disabilities. American Journal of Occupational Therapy, 34, 19-26.

Conscience, M., Schneider, J.-B., \& Brasseur, G. (2003). Construction du langage à l'école maternelle: prévention des difficultés de langage. 3 à 6 ans. Strasbourg: Access.

Cook, J., Saygin, A.P., Swain, R., \& Blakemore, S.-J. (2009). Reduced sensitivity to minimum-jerk biological motion in autism spectrum conditions. Neuropsychologia, 47, 3275-3278.

Chanquoy, L. (2005). Statistiques appliquées à la psychologie et aux sciences humaines et sociales. Paris: Hachette.

Dapretto, M., Davies, M. S., Pfeifer, J. H., Scott, A. A., Sigman, M., Bookheimer, S. Y., \& Iacoboni, M. (2005). Understanding emotions in others: Mirror neuron dysfunction in children with autism spectrum disorders. Nature Neuroscience, 9, 28-30.

Dawson, G., \& Adams, A. (1984). Imitation and social responsiveness in autistic children. Journal of Abnormal Child Psychology, 12, 209-226.

Dawson, G., Webb, S.J., \& McPartland, J. (2005). Understanding the Nature of Face Processing Impairment in Autism: Insights From Behavioral and Electrophysiological Studies. Developmental Neuropsychology, 27, 403-424.

DeMeyer, M.K., Alpern, G.D., Barton, S., DeMyer, W.E., Churchill, D.W., Hingtgen, J.N., Bryson, C.Q., Pontius, W., \& Kimberlin, C. (1972). Imitation in autistic, early schizophrenic, and non-psychotic subnormal children. Journal of Autism and Child Schizophrenia, 2, 264-287.

Dewey, D., Cantell, M., \& Crawford, S.G. (2007). Motor and gestural performance in children with autism spectrum disorders, developmental coordination disorder, and/or attention deficit hyperactivity disorder. Journal of the International Neuropsychological Society, 13,246-256. 
Dowell, L.R., Mahone, E.M., \& Mostofsky, S.H. (2009). Associations of postural knowledge and basic motor skill with dyspraxia in autism: Implication for abnormalities in distributed connectivity and motor learning. Neuropsychology, 23, 563-570.

Dunn, L. M., Thériault-Whalen, C. M., \& Dunn, L. M. (1993). Échelle de vocabulaire en image Peabody. Circle Pines: American Guidance Services.

Fombonne, E. (2003). Epidemiological surveys of autism and other pervasive developmental disorders: An update. Journal of Autism and Developmental Disorders, 33, 365-382.

Freitag, C. M., Konrad, C., Häberlen, M., Kleser, C., von Gontard, A., Reith, W., Troje, N. F., $\&$ Krick, C. (2008). Perception of biological motion in autism spectrum disorders. Neuropsychologia, 46, 1480-1494.

Gepner, B., Deruelle, C., \& Grynfelt, S. (2001). Motion and emotion: a novel approach to the study of face processing by young autistic children. Journal of Autism and Developmental Disorders, 31, 37-45.

Gepner, B., \& Mestre, D. (2002a). Rapid visual-motion integration deficit in autism. Trends in Cognitive Sciences, 6, 455.

Gepner, B. \& Mestre, D. (2002b). Brief Report: Postural reactivity to fast visual motion differentiates autistic from children with Asperger syndrome. Journal of Autism and Developmental Disorders, 32, 231-238.

Gepner, B., Mestre, D., Masson, G., \& de Schonen, S. (1995). Postural effects of motion vision in young autistic children. NeuroReport, 6, 1211-1214.

Gepner, B. \& Féron, F. (2009). Autism: a world changing too fast for a mis-wired brain? Neuroscience and Biobehavioral Reviews, 33, 1227-1242.

Girard, B. (1996). Développement langagier. In R. Leduc (Ed.), Etapes du développement de l'enfant et suggestions d'intervention. Pour un dépistage précoce et continu réussi (pp. 61-86). Ontario: CFORP.

Gowen, E., Stanley, J., \& Miall, R.C. (2008). Movement interference in autism-spectrum disorder. Neuropsychologia, 46, 1060-1068.

Grandin T., 1995. Thinking in pictures and other reports from my life with autism, New York: Vintage Books.

Green, D., Baird, G., Barnett, A. L., Henderson, L., Huber, H., \& Henderson, S. E. (2002). The severity and nature of motor impairment in Asperger's syndrome: A comparison with specific developmental disorder of motor function. Journal of Child Psychology and Psychiatry, 43, 655-668.

Grézès, J., Costes, N., \& Decety, J. (1999). The effects of learning and intention on the neural network involved in the perception of meaningless actions. Brain, 122, 1875-1887.

Grudnik, J.L., \& Kranzler, J.H. (2001). Meta-analysis of the relationship between intelligence and inspection time. Intelligence, 29, 523-535.

Hadjikhani, N., Joseph, R.M., Snyder, J., \& Tager-Flusberg, H. (2007). Abnormal activation of the social brain during face perception in autism. Human Brain Mapping, 28, 441-449.

Heimann, M., \& Ullstadius, E. (1999). Neonatal imitation and imitation among children with autism and Down's syndrome. In J. Nadel \& G. Butterworth (Eds.), Imitation in infancy (pp. 235-253). New York: Cambridge University Press.

Heimann, M., Ullstadius, E., Dahlgren, S.O., \& Gillberg, C. (1992). Imitation in autism: A preliminary research note. Behavioural Neurology, 5, 219-227.

Henderson, S.E., Morris, J., \& Frith, U. (1981). The motor deficit in Down's syndrome children: A problem of timing? Journal of Child Psychology and Psychiatry, 22, 233245.

Herrington, J. D., Baron-Cohen, S., Wheelwright, S. J., Singh, K. D., Bullmore, E. T., Brammer, M., \& Williams, S. C. R. (2007). The role of MT+/V5 during biological 
motion perception in Aperger syndrome: An fMRI study. Research in Autism Spectrum Disorder, 1, 14-27.

Howell, D.C. (2009). Statistical Methods for Psychology. Belmonte, CA: Wadsworth Publishing.

Kail, R. (1992). General slowing of information-processing by persons with mental retardation. American Journal of Mental Retardation, 97, 333-341.

Kaiser M.D., \& Shiffrar M. (2009). The visual perception of motion by observers with autism spectrum disorders: A review and synthesis. Psychonomic Bulletin \& Review, 16, 761777.

Kaufman, A., \& Kaufman, N. L. (1993). Batterie pour l'examen psychologique de l'enfant $(K-A B C)$. Paris: ECPA.

Klin, A., Jones, W., Schultz, R., \& Volkmar, F. (2004). Letter to the Editor: Dr Klin and colleagues reply. American Journal of Psychiatry, 161, 1719-1720.

Klin A., Lin D.J., Gorrindo P., Ramsay G., \& Jones W. (2009). Two-year-olds with autism orient to non-social contingencies rather than biological motion. Nature, 459, 257-261.

Lainé, F., Tardif, C., \& Gepner, B. (2008a). Amélioration de la reconnaissance et de l'imitation d'expressions faciales chez des enfants autistes grâce à une présentation visuelle et sonore ralentie. Annales Médico-Psychologiques, 166, 533-538.

Lainé, F., Tardif, C., Rauzy, S., \& Gepner, B. (2008b). Perception et imitation du mouvement dans l'autisme: Une question de temps. Enfance, 2, 140-157.

Leighton, J., Bird, G., Charman, T., \& Heyes, C. (2008). Weak imitative performance is not due to a functional 'mirroring' deficit in adults with autism spectrum disorders. Neuropsychologia, 46, 1041-1049.

Libby, S., Powell, S., Messer, D., \& Jordan, R. (1997). Imitation of pretend play acts by children with autism and Down syndrome. Journal of Autism and Developmental Disorders, 27, 365-383.

McCleery, J.P., Allman, E., Carver, L.J., \& Dobns, K.R. (2007). Abnormal magnocellular pathway visual processing in infants at risk for autism. Biological Psychiatry, 62, 10071014.

McPartland, J., Dawson, G., Webb, S.J., Panagiotides, H., \& Carver, L.J. (2004). Eventrelated brain potentials reveal anomalies in temporal processing of faces in autism spectrum disorder. Journal of Child Psychology and Psychiatry, 45, 1235-1245.

Meltzoff, A.N., (2007). The 'like me' framework for recognizing and becoming an intentional agent. Acta Psychologica, 124, 26-43.

Milne, E., Swettenham, J., Hansen, P., Campbell, R., Jeffries, H., \& Plaisted, K. (2002). High motion coherence thresholds in children with autism. Journal of Child Psychology and Psychiatry, 43, 255-263.

Mostofsky, S.H., Dubey, P., Jerath, V.K., Jansiewicz, E.M., Goldberg, M.C., \& Denckla, M.B. (2006). Developmental dyspraxia is not limited to imitation in children with autism spectrum disorders. Journal of the International Neuropsychological Society, 12, 314-326.

Nadel, J. (2006). Does imitation matter to children with autism? In S. J. Rogers \& J. H. G. Williams (Eds.), Imitation and the social mind. Autism and typical development (pp. 118-137). New York: Guilford Publications.

Nadel, J., \& Pezé, A. (1993). What makes immediate imitation communicative in toddlers and autistic children. In J. Nadel \& L. Camaioni (Eds.), New perspectives in early communicative development (pp. 139-158). London: Routledge.

Nadel, J., \& Potier, C. (2002). Imiter et être imité dans le développement de l'intentionnalité. In J. Nadel \& J. Decety (Eds.), Imiter pour découvrir l'humain: Psychologie, neuropsychologie, robotique et philosophie de l'esprit (pp. 83-104). Paris: PUF. 
Nadel, J., Guérini, C., Pezé, A., \& Rivet, C. (1999). The evolving nature of imitation as a format for communication. In J. Nadel \& G. Butterworth (Eds.), Imitation in infancy (pp. 209-234). New York: Cambridge University Press.

Nadel, L. (1999). Down syndrome in cognitive neuroscience perspective. In H. TagerFlusberg (Ed.), Neurodevelopmental disorders (chap. 9, pp.197-222). Cambridge: MIT Press.

Nishitani, N., Avikainen, S., \& Hari, R. (2004). Abnormal imitation-related cortical activation sequences in Asperger's syndrome. Annals of Neurology, 55, 558-562.

Oberman, L.M., \& Ramachandran, V.S. (2007). The simulating social mind: The role of the mirror neuron system and simulation in the social and communicative deficits of autism spectrum disorders. Psychological Bulletin, 133, 310-327.

Oberman, L.M., Hubbard, E.M., McCleery, J.P., Altschuler, E.L., Ramachandran, V.S., \& Pineda, J.A. (2005). EEG evidence for mirror neuron dysfunction in autism spectrum disorders. Cognitive Brain Research, 24, 190-198.

Ohta, (1987). Cognitive disorders of infantile autism: A study employing the WISC, spatial relationship, conceptualization, and gestural imitations. Journal of Autism and Developmental Disorders, 17, 45-62.

Osterling, J., \& Dawson, G. (1994). Early recognition of children with autism: A study of first-birthday home videotapes. Journal of Autism and Developmental Disorders, 24, 247-257.

Pilowski, T., Yirmiya, N., Shulman, C., \& Dover, R. (1998). The Autism Diagnostic Interview-Revised and the Childhood Autism Rating Scale: Differences between diagnostic systems and comparison between genders. Journal of Autism and Developmental Disorders, 28, 143-151.

Raven, J. (1981). Progressive Matrice Coloured Test. Issy-les-Moulineaux : EAP, Expansions Scientifiques et Psychologiques.

Rinehart, N., Tonge, B., Brereton, A., \& Bradshaw, J. (2010). Attentional blink in young people with high-functioning autism and Aperger's disorder. Autism, 14, 47-66.

Rogers, S. J., \& Pennington, B. F. (1991). A theoretical approach to the deficits in infantile autism. Development \& Psychopathology, 3, 137-162.

Rogers, S.J., Bennetto, L., McEvoy, R., \& Pennington, B.F. (1996). Imitation and pantomime in high-functioning adolescents with autism spectrum disorders. Child Development, 67, 2060-2073.

Rogers, S. J., Hepburn, S. L., Stackhouse, S., \& Wehner, E. (2003). Imitation performance in toddlers with autism and those with developmental disorders. Journal of Child Psychology and Psychiatry, 44, 763-781.

Rogers, S.J., Young, G.S., Cook' I., Giolzetti, A., \& Ozonoff, S. (2010). Imitating actions on objects in early-onset and regressive autism: Effects and implications of task characteristics on performance. Development and Psychopathology, 22, 71-85.

Rumiati, R.I., \& Tessari, A. (2002). Imitation of novel and well-known actions. The role of short-term memory. Experimental Brain Research, 142, 425-433.

Russell, J. A. (1990). The preschooler's understanding of the causes and consequences of emotion. Child Development, 61, 1872-1881.

Saemundsen, E., Magnússon, P., Smári, J., \& Sigurdardóttir, S. (2003). Autism Diagnostic Interview-Revised and the Childhood Autism Rating Scale: Convergence and discrepancy in diagnosing autism. Journal of Autism and Developmental Disorders, 33, 319-328.

Schopler, E., Reichler, R. J., DeVellis, R. F., \& Daly, K. (1980). Toward objective classification of childhood autism: Childhood Autism Rating Scale (CARS). Journal of Autism and Developmental Disorders, 10, 91-103. 
Schopler, E., Reichler, R. J., Bashford, A., Lansing, M. D., \& Marcus, L. M. (1994). Profil psycho-éducatif (PEP-R). Evaluation et intervention individualisée pour enfants autistes ou présentant des troubles du développement. Brussels: De Boeck University.

Sevlever, M. \& Gillis, J.M. (2010). An examination of the state of imitation research in children with autism: Issues of definition and methodology. Research in Developmental Disabilities, 31, 976-984.

Sherman, S. L., Allen, E. G., Bean, L. H., \& Freeman, S. B. (2007). Epidemiology of Down syndrome. Mental Retardation and Developmental Disabilities Research Reviews, 13, 221-227.

Shih, P., Shen, M., Öttl, B., Keehn, B., Gaffrey, M.S., \& Müller, R-A. (2010). Atypical network connectivity for imitation in autism spectrum disorder. Neuropsychologia, doi:10.1016/j.neuropsychologia.2010.05.035.

Sigman, M., \& Ungerer, J. A. (1984). Cognitive and language skills in autistic, mentally retarded and normal children. Developmental Psychology, 20, 293-302.

Smith, I.M. \& Bryson, S.E. (1994). Imitation and Action in Autism: A Critical Review. Psychological Bulletin, 114, 259-273.

Smith, I. M., \& Bryson, S. E. (1998). Gesture imitation in autism. I: Nonsymbolic postures and sequences. Cognitive Neuropsychology, 15, 747-770.

Spanò, M., Mercuri, E., Rando, T., Pantò, T., Gagliano, A., Henderson, S., \& Guzetta, F. (1999). Motor and perceptual-motor competence in children with Down syndrome: variation in performance with age. European Journal of Paediatric Neurology, 3, 7-13.

Spencer, J., O’Brien, J., Riggs, K., Braddick, O., Atkinson, J., \& Wattam-Bell, J. (2000). Motion processing in autism: Evidence for a dorsal stream deficiency. NeuroReport, 11, 2765-2767.

Steinman, K.J., Mostofsky, S.H., \& Denckla, M.B. (2010). Toward a narrower, more pragmatic view of developmental dyspraxia. Journal of Child Neurology, 25, 71-81.

Stieglitz Ham, H., Corley, M., Rajendran, G., Carletta, J., \& Swanson, S. (2008). Brief report: Imitation of meaningless gestures in individuals with Asperger syndrome and highfunctioning autism. Journal of Autism and Developmental Disorders, 38, 569-573.

Stieglitz Ham, H., Bartolo, A., Corley, M., Rajendran, G., Szabo, A., \& Swanson, S. (2010). Exploring the relationship between gestural recognition and imitation: Evidence of dyspraxia in autism spectrum disorders. Journal of Autism and Developmental Disorders, DOI: 10.1007/s10803-010-1011-1.

Stone, W.L., Ousley, O.Y., \& Littleford, C.D. (1997). Motor imitation in young children with autism: What's the object? Journal of Abnormal Child Psychology, 25, 475-485.

Tardif, C., Lainé, F., Rodriguez, M., \& Gepner, B. (2007). Slowing down presentation of facial movements and vocal sounds enhances facial expression recognition and induces facial-vocal imitation in children with autism. Journal of Autism and Developmental Disorders, 37, 1469-1484.

Vanvuchelen, M., Roeyers, H., \& De Weerdt, W. (2007). Nature of motor imitation problems in school-aged males with autism: how congruent are the error types? Developmental Medicine \& Child Neurology, 49, 6-12.

Villalobos, M.E., Mizuno, A., Dahl, B.C., Kemmotsu, N., \& Müller, R.-A. (2005). Reduced functional connectivity between V1 and inferior frontal cortex associated with visuomotor performance in autism. NeuroImage, 25, 916-925.

Vivanti, G., Nadig, A., Ozonoff, S., \& Rogers, S.J. (2008). What do children with autism attend to during imitation tasks? Journal of Experimental Child Psychology, 101, 186205.

Wallon, H. (1934). Les origines du caractère chez l'enfant. Paris: PUF. 
Webb, S.J., Dawson, G., Bernier, R., \& Panagiotides, H. (2006). ERP evidence of atypical face processing in young children with autism. Journal of Autism and Developmental Disorders, 36, 881-890.

Welsh, J.P., Ahn, E.S., \& Placantonakis, D.G. (2005). Is autism due to brain desynchronization? International Journal of Developmental Neuroscience, 23, 253-263.

Wild, K.S., Poliakoff, E., Jerrison, A., \& Gowen, E. (2010). The influence of goals on movement kinematics during imitation. Experimental Brain Research, DOI: 10.1007/s00221-009-2034-8.

Williams, D. (1992). Nobody nowhere: An extraordinary life of an autistic. New York: Times Book.

Williams, J. H. G., Whiten, A., \& Singh, T. (2004). A systematic review of action imitation in autistic spectrum disorder. Journal of Autism and Developmental Disorders, 34, $285-$ 299.

Zelazo, P.R., \& Stack, D.M. (1997). Attention and information processing in infants with Down syndrome. In J.A. Burack \& J.T. Enns (Eds.), Attention, Development and Psychopathology (chap. 6, pp. 123-146). New York: Guilford Press.

Zwaigenbaum, L., Bryson, S., Rogers, T., Roberts, W., Brian, J., \& Szatmari, P. (2005). Behavioral manifestations of autism in the first year of life. International Journal of Developmental Neuroscience, 23, 143-152. 
Appendix

Types of facial and body movements used in the study

1. Jump twice

2. Fold arms alternately at chest level

3. Raise arms above head

4. Strike each thigh with each hand in turn

5. One hand behind head, the elbow next to the torso, touch this elbow with the other hand, including a movement to the floor

6. Close eyes

7. Puff out cheeks

8. Stick tongue out

9. Open mouth a little

10. Close fist and move thumb up and down

11. Close hand (palm facing camera) into a fist, with the thumb over the other fingers

12. Stretch arms out in front of chest, with hands and arms parallel to the floor, and simultaneously and symmetrically move them in circles

13. Stretch out the fingers of one hand (horizontal, profile view). The thumb must then touch the other fingers one by one, beginning with the index and ending with the little finger, before returning to its initial position

14. With the palm facing the ceiling, join all fingers to form a kind of tunnel

15. Stretch out fingers, with palm facing the floor, then rotate hand until facing the ceiling

16. Hold arms at sides, then stretch them out towards the camera

17. Fold arm against torso, with index finger pointing to camera, then extend arm towards camera

18. Hold arm at side, then touch top of head with hand

19. Point to camera with index finger at head level, then touch nose

20. Hold arms folded at sides, then extend them until they are parallel with the floor, with hands perpendicular to arms

Sources of gestures:

Gestures 1, 2, 7 and 8 were derived from Beadle-Brown and Whiten's study (2004).

Gestures 4, 5, 6, 9, 10,11, 15, 17, 18, 19 and 20 were inspired by K-ABC items (Kaufman \& Kaufman, 1993).

Gestures 3, 13 and 14 were inspired by PEP-R items (Schopler, Reichler, Bashford, Lansing, \& Marcus, 1994). 1980).

Gestures 12 and 16 were derived from Gesture Test items (Cermak, Coster \& Drake, 
Author notes

France Lainé et Carole Tardif, Centre PsyCLE (Centre de Recherche en Psychologie de la Connaissance, du Langage et des Emotions), Université de Provence, Aix-en-Provence, France

Stéphane Rauzy, "Laboratoire Parole et Langage”, CNRS UMR 6057, Université de Provence, Aix-en-Provence, France

Bruno Gepner, "Laboratoire Parole et Langage", CNRS UMR 6057, Université de Provence and Fédération Autisme Vie Entière, Hôpital Montperrin, Aix-en-Provence, France

France Lainé is now at affiliation: Department of Educational and Counseling Psychology, McGill University, 3700 McTavish Street, Montreal H3A 1Y2, Quebec, Canada.

This research was partially supported by a grant from the multidisciplinary "Cognition et Traitement de l'Information" CNRS program and by an Orange Foundation grant to France Lainé for her PhD in psychology. We would like to thank the MA psychology students Hélène Teyssèdre, Camille DeMaupéou, Akselle DiBattista and Anne-Laurie NDjikessi for their help with the testing and data analysis. We are also grateful to Philippe Blache, director of the "Laboratoire Parole et Langage", for his scientific contribution, and to Pr. Jacob A. Burack, Department of Educational and Counseling Psychology, McGill University, for his helpful comments on the manuscript.

Correspondence concerning this article should be addressed to: France Lainé, Department of Educational and Counseling Psychology, McGill University, 3700 McTavish street, Montreal, Quebec, H3A 1Y2, Canada. E-mail address: france.laine@ univ-provence.fr. Telephone number: + 514398 8273, or to Bruno Gepner (bruno.gepner@univ-provence.fr).

Table 1

Characteristics of the participants in the four groups

\begin{tabular}{|c|c|c|c|c|c|}
\hline $\begin{array}{l}\text { Group } \\
\text { (size) }\end{array}$ & $\begin{array}{c}\text { Sex ratio } \\
(\mathrm{F} / \mathrm{M})\end{array}$ & $\begin{array}{l}\text { Chronological } \\
\text { age } \\
\text { Mean (S.D.) } \\
\text { Range } \\
\end{array}$ & $\begin{array}{c}\text { VMA } \\
\text { Mean (S.D.) } \\
\text { Range }\end{array}$ & $\begin{array}{c}\text { NVMA } \\
\text { Mean (S.D.) } \\
\text { Range }\end{array}$ & $\begin{array}{c}\text { CARS } \\
\text { Mean (S.D.) } \\
\text { Range }\end{array}$ \\
\hline $\begin{array}{l}\text { AUT } \\
(\mathrm{N}=19)\end{array}$ & $4 / 15$ & $\begin{array}{c}11 ; 8(3 ; 8) \\
6 ; 4-17 ; 6\end{array}$ & $\begin{array}{l}4 ; 6(2 ; 1) \\
2 ; 1-10 ; 0\end{array}$ & $\begin{array}{c}6 ; 10(2 ; 4) \\
3 ; 9-12 ; 6\end{array}$ & $\begin{array}{c}36,05(1,92) \\
31-38,5\end{array}$ \\
\hline $\begin{array}{l}\text { C-VMA } \\
(\mathrm{N}=19)\end{array}$ & $4 / 15$ & $\begin{array}{c}4 ; 7(1 ; 11) \\
2 ; 2-10 ; 1\end{array}$ & $\begin{array}{l}4 ; 6(2 ; 0) \\
2 ; 1-10 ; 1\end{array}$ & I & I \\
\hline $\begin{array}{l}\text { C-NVMA } \\
(\mathrm{N}=18)\end{array}$ & $5 / 13$ & $\begin{array}{c}6 ; 10(2 ; 5) \\
3 ; 9-12 ; 6\end{array}$ & I & $\begin{array}{c}6 ; 10(2 ; 5) \\
3 ; 9-12 ; 6\end{array}$ & I \\
\hline $\begin{array}{l}\text { C-DS } \\
(\mathrm{N}=17)\end{array}$ & $6 / 11$ & $\begin{array}{r}14 ; 5(3 ; 5) \\
6 ; 11-19 ; 11\end{array}$ & I & $\begin{array}{c}6 ; 2(1 ; 9) \\
3 ; 0-9 ; 6\end{array}$ & I \\
\hline
\end{tabular}


Table 2

Distribution of the participants of the experimental and control groups in function of the VMA, the NVMA and the severity of autism

\begin{tabular}{lccccccccc}
\hline Sample & \multicolumn{3}{c}{ Autism severity (CARS) } & \multicolumn{3}{c}{ NVMA (K-ABC and } & \multicolumn{3}{c}{ VMA (EVIP) } \\
& \multicolumn{3}{c}{} & \multicolumn{3}{c}{ PMC-T) } & \multicolumn{3}{c}{ High } \\
\cline { 2 - 10 } & Severe & Moderate & Mild & Low & Middle & High & Low & Middle & High \\
\hline AUT & 6 & 7 & 6 & 6 & 7 & 6 & 7 & 9 & 3 \\
C-VMA & & & & & & & 7 & 9 & 3 \\
C-NVMA & & & & 5 & 7 & 6 & & & \\
C-DS & & & & 5 & 7 & 5 & & & \\
\hline
\end{tabular}

Legend: In subdivision according to the autism severity, the "severe" subgroup includes children with a CARS's score above 37; the "moderate" subgroup includes children with a score between 35.5 and 37 ; and the "mild" subgroup includes children with a score between 30 and 35. Note that the notion of severe autism was relative here, for the CARS threshold for severe autism is 38.5 and scores can be as high as 60 for the most severe cases. In subdivision according to the NVMA, the "low" NVMA includes children with an NVMA inferior to 5 years; the "middle" NVMA includes children with an NVMA between 5;1 years and 7;0 years; and the "high" NVMA includes children with an NVMA between 7;1 years and 12;6 years.

In subdivision according to the VMA, the "low" VMA includes children with a VMA inferior to 4 years; the "middle" VMA includes children with a VMA between 4;1 years and 7;0 years; and the "high" VMA includes children with a VMA between 7;1 years and 10;1 years.

Table 3

Number of children of each group with different levels of autism severity, NVMA and/or VMA helped by slower presentations

\begin{tabular}{llccccccccc}
\hline & \multicolumn{3}{c}{ Autism severity } & \multicolumn{3}{c}{ NVMA } & \multicolumn{3}{c}{ VMA } \\
\cline { 2 - 10 } & Severe & Moderate & Mild & Low & Middle & High & Low & Middle & High \\
\hline AUT & $6-0$ & $2-5$ & $2-4$ & $5-1$ & $3-4$ & $2-4$ & $6-1$ & $2-7$ & $2-1$ \\
C-VMA & & & & & & & $6-1$ & $4-5$ & $1-2$ \\
C-NVMA & & & & $2-3$ & $2-5$ & $3-3$ & & & \\
C-DS & & & & $1-4$ & $5-2$ & $1-4$ & & & \\
\hline
\end{tabular}

Legend: The numbers represent the distribution of participants helped (to the left of the pair of numbers)-non helped (to the right of the pair of numbers) by slowed presentations. 
Figure 1: Example of movements from each type of spheres (face, hand, arm, and body)

Figure 2: Mean imitation scores (and standard deviations) of all four groups: Typicallydeveloping children group matched to children with autism on Verbal Mental Age (C-VMA), typically-developing children group matched to children with autism on Nonverbal Mental Age (C-NVMA), children with Down syndrome group matched to children with autism on Nonverbal Mental Age (C-DS) and children with Autism group (AUT)

Figure 3: Mean imitation scores (and standard deviations) of the four groups (C-VMA, CNVMA, C-DS and AUT) according to the speed of presentation (S1, S2, S3) 
Figure 1 Top

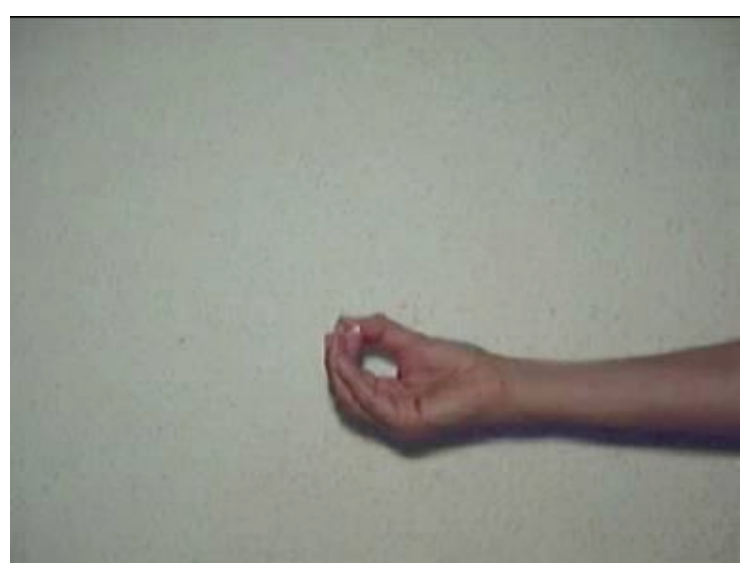

Hand movements

(thumb touches all the other fingers simultaneously)

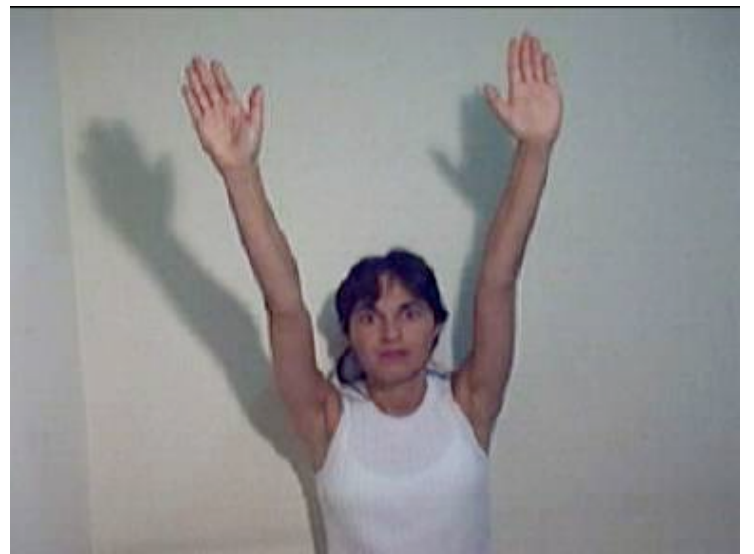

Arms movement (raise arms above head)

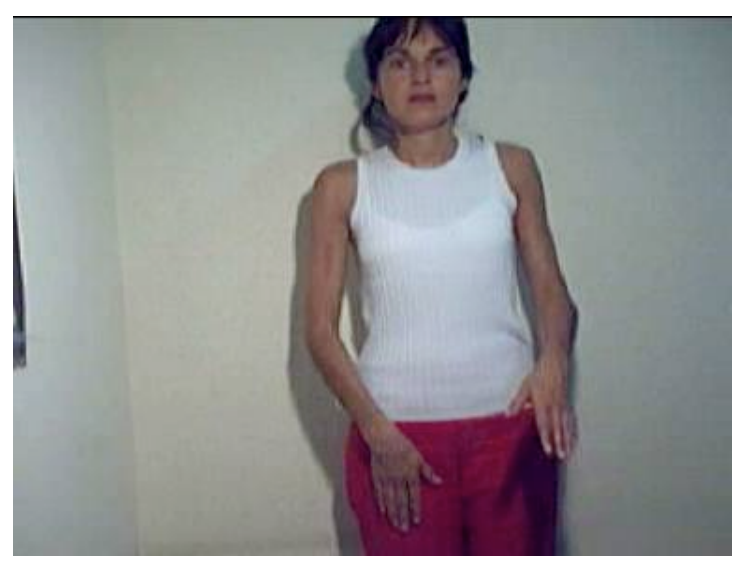

Body movement

(hands strike each thigh in turn)

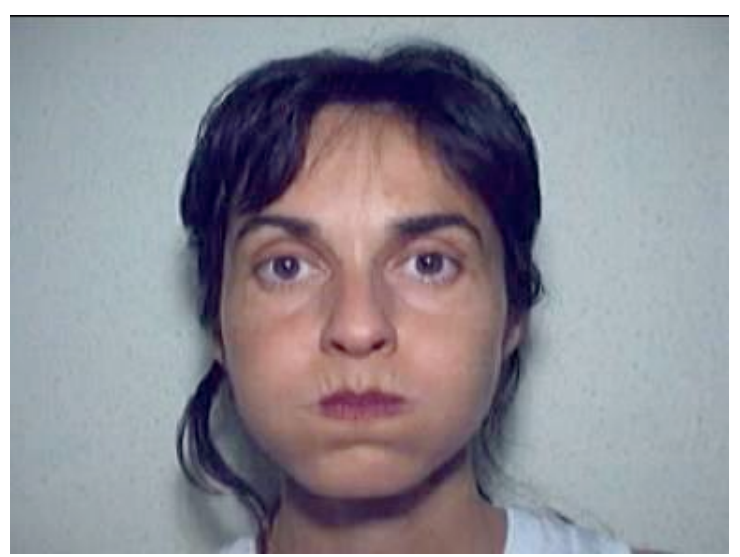

Facial movement (puff out cheeks) 
Figure 2 Top

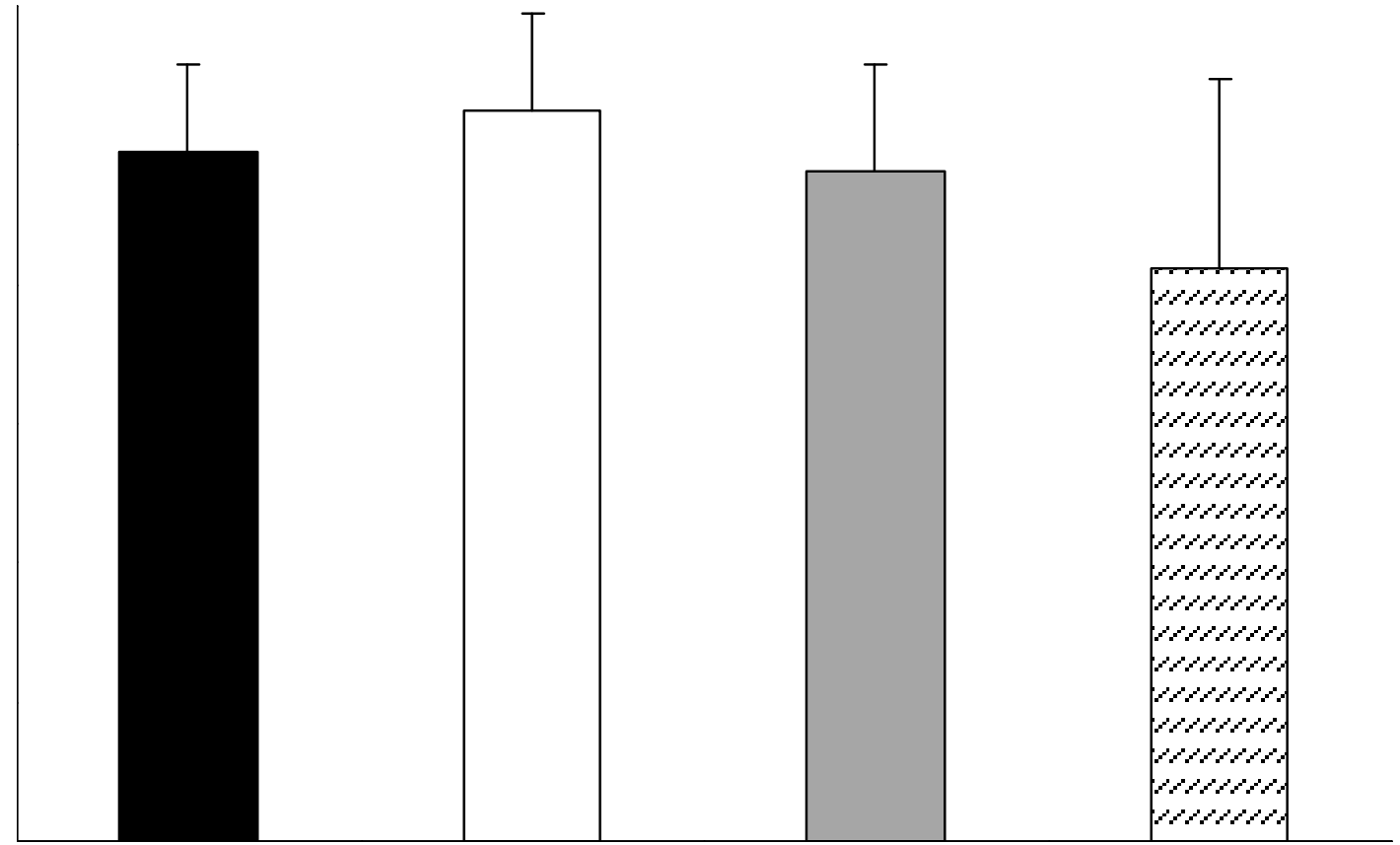

Figure 3 Top 


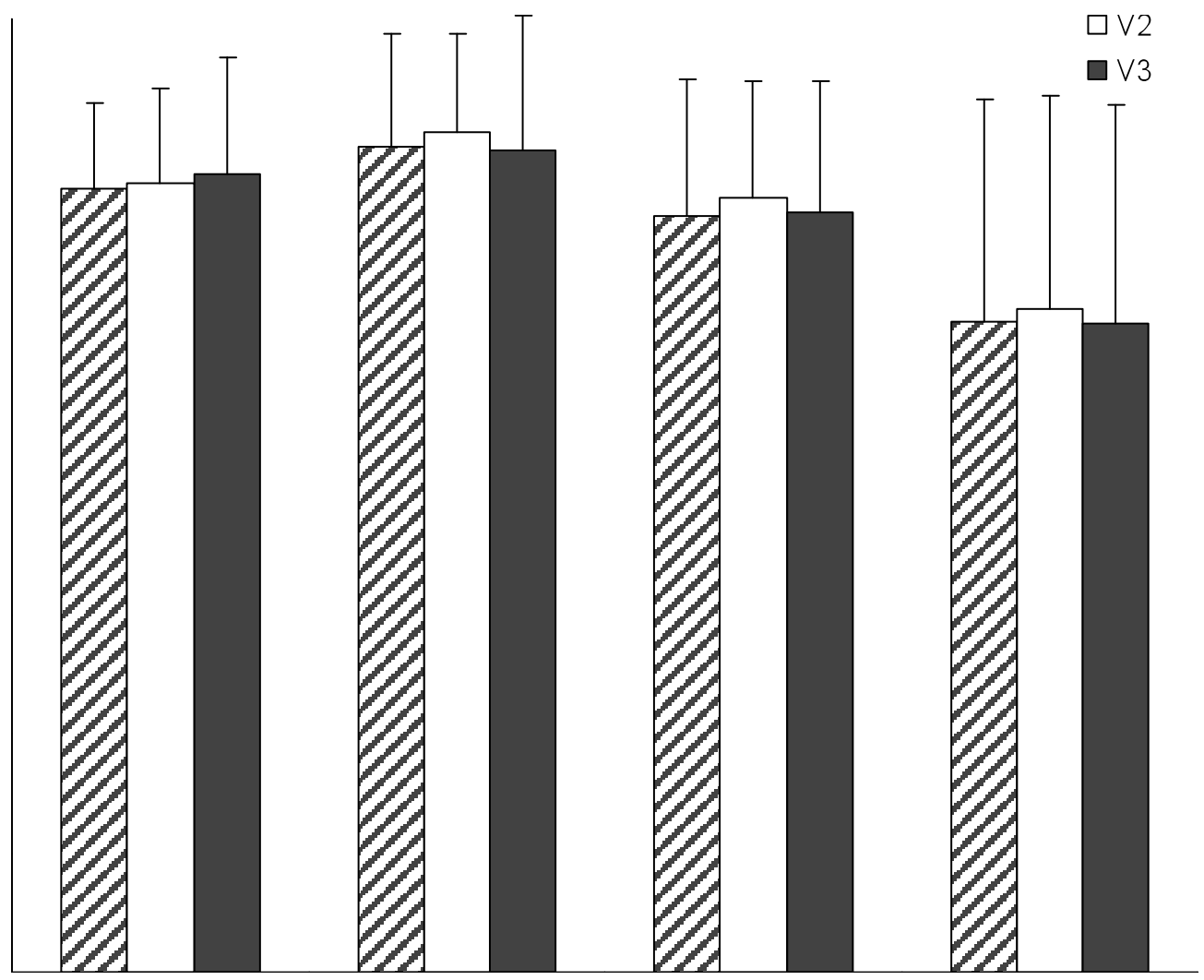

